\title{
Retrospective evaluation of geriatric patients treated at burn intensive care unit
}

\begin{abstract}
Burns in geriatric patients are an important trauma. In this study, it was aimed to evaluate the geriatric cases discharged from burn intensive care unit. Twelve cases of scald and flame burnt, ages of the patients between 65 and over and percentages of the burn damages between $\% 10$ and $32 \%$. The sex ratio of patients was male-female and the age of the patients was between 65-87. All the patients had scald and the flame burns. The best way to reduce burn-related mortality in geriatric patients is to protect from burns. Geriatric burn injury; it is mostly a home-based trauma that can be prevented. We think that treatment of severe burned geriatric patients in fully equipped treatment centers will reduce mortality.
\end{abstract}

Keywords: burn, elderly, intensive care
Volume 3 Issue 3 - 2018

\section{Serkan Uckun, Tamer Kuzucuoglu, Salih Gunbegi}

Anesthesiology and Reanimation, University of Health Sciences Kartal Dr. Lutfi Kırdar Training and Research Hospital,Turkey

Correspondence: Serkan Uçkun, Anesthesiology and Reanimation, University of Health Sciences Kartal Dr. Lutfi Kırdar Training and Research Hospital, Cevizli, Istanbul, Turkey, Tel +90535370 I I64, Email serkanuckun@yahoo.com

Received: May 30, 2018 | Published: June 13, 2018

\section{Introduction}

Senility; is one of the natural and mandatory periods of human life such as childhood, youth, and adulthood. ${ }^{1}$ Aging is accompanied by a gradual reduction in the functional reserves of all organ systems. The starting time and size of these changes are very different from person to person. In the large majority of senile patients, physiological compensation is adequate for age-related changes, but limitation in physiological reserves occurs during periods of stress such as exercise, illness and perioperative. ${ }^{2}$ Burn; is an important public health problem that leads to acute morbidity and mortality that requires intensive care and treatment processes that can be seen all over the world. The epidemiological and demographic character of burn injury differs from country to country, but it causes many medical, psychological, social and economic problems in all societies. In our study; demographic data and hospitalization times of 12 patients over 65 years of age who were treated and discharged in our burn intensive care unit (ICU) were discussed in the light of the literature.

\section{Materials and method}

Twelve cases of scald and flame burn between 65 and over between 10 and $32 \%$ of working age were included. The files of the patients were retrospectively scanned. Patients' age, sex, percentage of burns, duration of ICU admission, APACHE (Acute Physiology and Chronic Health Evaluation) II score and ABSI (Abbreviated Burn Severity Index) score was evaluated. The results were analyzed with the SPSS 22.0 statical program.

\section{Results}

The sex ratio of patients was 8 male- 4 female and the age of the patients was between 65-87. All the patients had scald and the flame burnt. The percent of burn varied between $10 \%$ and $32 \%$ and mean was $17.9 \pm 7,0$. Patients' APACHE II score was $7.4 \pm 0,99$ and ABSI score was $18.9 \pm 2,15$. Mean hospitalization duration was $19.75 \pm 17.49$ days. The datas of the patients were summarized at Table 1 .

Table I Summary of case parameters

\begin{tabular}{|c|c|c|c|c|c|c|}
\hline Age & Sex & Burn percentage (\%) & $\begin{array}{l}\text { Hospitalization duration } \\
\text { (Days) }\end{array}$ & Additional illness & ABS I & APACHE II \\
\hline 80 & M & 10 & 26 & DM, HT & 7 & 21 \\
\hline 65 & M & 13 & 5 & $\mathrm{DM}, \mathrm{HT}, \mathrm{CHF}$ & 6 & 20 \\
\hline 65 & M & 20 & 4 & & 6 & 18 \\
\hline 78 & M & 24 & 22 & & 7 & 20 \\
\hline 82 & M & 32 & 20 & & 9 & 20 \\
\hline 87 & $\mathrm{~F}$ & 15 & 10 & DM, HT & 8 & 15 \\
\hline 65 & $\mathrm{~F}$ & 20 & 60 & DM, HT,CHF, Asthma & 7 & 20 \\
\hline 74 & M & 28 & 43 & & 9 & 15 \\
\hline 86 & $\mathrm{~F}$ & 15 & 20 & & 8 & 18 \\
\hline 76 & M & 10 & 22 & & 7 & 21 \\
\hline 72 & $\mathrm{~F}$ & 15 & 2 & $\mathrm{DM}, \mathrm{HT}, \mathrm{CHF}$ & 7 & 21 \\
\hline 79 & $M$ & 13 & 3 & & 8 & 18 \\
\hline
\end{tabular}

DM, Diabetes Mellitus; HT, Hypertension; CHF, Congestive heart failure 


\section{Discussion}

Significant progress has been made in the treatment of burns in recent years, but the improvement of health outcomes in elderly adults with burn injuries is much lower than that of young patients. As with any disease group burn injuries have an important effect on both age and burn formation as well as treatment outcomes. The elderly people are more exposed to burn injuries because of their decreased ability to move along with their advancing age, inability to perform fine motor functions, and decrease in reflexes. Burn in elderly patients; the fourth of deaths related to the causes of injury. Mabrouk et al. ${ }^{3}$ In their study; reported that $23.7 \%$ of elderly patient's abilites to escape and survive were limited and stay unable to move at the scene of accident and this caused increase the severity of injuries in the hospital. ${ }^{3}$ Necessary precautions should be taken to prevent these preventable complications, such as burning conditions. ${ }^{4}$

In elderly patients; lack of adaptation to each kind of stres and often existing of concomitant diseases affects negatively the treatment of the burn injury and the results of the treatments. ${ }^{5}$ The surgical and medical interventions used remain controversial, and debates are ongoing. ${ }^{6}$ We have observed that the duration of hospitalization is prolonged because of the concommitant disease at 5 of our patients.

There was no consensus in the literature in studies that examine the relationship between gender and mortality in geriatric burn patients. Haberal et al., ${ }^{7}$ found that male / female ratio of burn patients was 2.6: 1 in their study. Some researchers have reported female gender as a risk factor, but reported no significant relationship between gender and mortality. ${ }^{8,9}$ In the study of Brusselaers el al; male mortality rates that were higher but statistically insignificant compared to women were reported. ${ }^{10}$ Mc Gwin et al., ${ }^{11}$ determined about the fact of the high mortality in female patients independently from demographic characters, burn etiology and burn severity and put the blame on suppression of cellular immunity after thermal injury and the higher estrogen levels. In our study, 8(66.6) of the geriatric patients were male and 4(33.4\%) were female.

There is a consensus in the literature regarding the increase in the total burn area and mortality. It is noteworthy that the mortality rate of geriatric patients with a burn width greater than $50 \%$ was observed. In the study of Kurtoğlu et al. ${ }^{12}$ The percentage of burns of patients was classified as $30-50 \%, 50-75 \%$, and $>75 \%$, and mortality rates were determined as; $66 \%, 95 \%$ and $100 \% .^{12}$ Ryan et al. reported that it is an element of risk for the mortality if percentage of the burn injury over $\% 40 .{ }^{13}$ Our facts were the patients who have burn areas between $\% 10$ and 32. The longest hospitalization period was the 65 years old female patient with more than two komorbid disease and $\% 20$ burn percentage. In the study of the Kala et al., ${ }^{14}$ if the burn injury is less than $\% 50$, the approximate hospitalization duration is decreased and the reason of decrease of the hospitlization duration is connected to early period mortalizaton of patients who has higher burn percentages..$^{14}$
Conclusion: The best way to avoid mortality caused by burn injury at geriatric patients is to avoid burns. Geriatric burn damage; is a trauma which mostly occurs at domestic environments and it can be prevented. We believe that the medication of the geriatric patients who have serious burns at fully equipped burn medical centers reduces the mortality.

\section{Acknowledgements}

None.

\section{Conflict of interest}

Author declares that there is no conflict of interest

\section{References}

1. Arslan Ş, Atalay A, Gökçe KY. Yaşlılarda ilaç tüketimi. Geriatri. 2000;3(2):56-60.

2. Steinmetz J, Rasmussen LS. Theelderlyand general anesthesia. Minerva anestesiologica. 2010;76(9):745-52.

3. Mabrouk A, Maher A, Nasser S. An epidemiologic study of elderly burn patients in Ain Shams University Burn Unit, Cairo, Egypt. Burns. 2003;29(7):687-690.

4. Yuce Y, Erkal K. Bir okul laboratuvar patlamasına bağlı yanıkların analizi. Sakarya Tıp Dergisi. 2018;8(1):141-148.

5. Jeschke MG, Patsouris D, Stanojcic M, et al. Pathophysiologic response to burns in the elderly. E Bio Medicine. 2015;2(10):1536-48.

6. Abu-Sittah FM, Chahine H, Janom H. Management of burns in the elderly. Ann Burns Fire Disasters. 2016. 29(4):249-245.

7. Haberal M, Uçar N, Bilgin N. Epidemiological survey of burns treated in ankara, turkey and desirable burn prevention strategies. J WoundCare. 1995;21(8):601-6.

8. Alison K, Porter K. Consensus on the pre-hospital approach to burns patient management. International Journal of the Care of the Injured. 2004;35(8):734-8.

9. Greenhalgh DG. Burn resuscitation: The results of the ISBI/ABA survey. Journal of Burns. 2010;36(2):176-82.

10. Duman H. Yanık Şoku Ve Sıvı Tedavisi. Türkiye Klinikleri J PlastSurg. 2010;2(1):78-84.

11. McGwin C, George RL, Cross JM, et al. Gender diferrences in mortality following burn injury. Shock. 2002;18(4):311-5.

12. Kurtoğlu M, Alimoğlu O, Ertekin C. Evaluation of severe burns managed in intensive care unit. Ulus Travma Acil Cerrahi Derg. 2003;9(1):34-36

13. Ryan CM, Schoenfeld DA, Thorpe WP, et al. Objective estimates of the probability of death from burn injuries. Engl J Med. 1998;338(6):362-6.

14. Kala PC. High tension electric injuries in western rajasthan: a review of 238 patients. New Indian Journal of Surgery. 2011; 3:141-15. 